\title{
Portals of Change: How Patient Portals Will Ultimately Work for Safety Net Populations
}

Alejandra Casillas ${ }^{1}$, MD, MSc; Anshu Abhat ${ }^{2}, \mathrm{MD}, \mathrm{MPH}$; Anish Mahajan ${ }^{2}, \mathrm{MD}, \mathrm{MSc}$; Gerardo Moreno ${ }^{3}, \mathrm{MD}, \mathrm{MSc}$; Arleen F Brown ${ }^{1}$, MD, PhD; Sara Simmons ${ }^{2}$, BSc; Peter Szilagyi ${ }^{4}$, MD, MPH

\footnotetext{
${ }_{1}^{1}$ Division of General Internal Medicine and Health Services Research, David Geffen School of Medicine, Los Angeles, CA, United States

${ }^{2}$ Los Angeles County Department of Health Services, Los Angeles, CA, United States

${ }^{3}$ Department of Family Medicine, David Geffen School of Medicine, Los Angeles, CA, United States

${ }^{4}$ Department of Pediatrics, David Geffen School of Medicine, Los Angeles, CA, United States
}

\section{Corresponding Author:}

Alejandra Casillas, MD, MSc

Division of General Internal Medicine and Health Services Research

David Geffen School of Medicine

1100 Glendon Avenue

Ste 850

Los Angeles, CA, 90024

United States

Phone: 13107940150

Email: acasillas@mednet.ucla.edu

\begin{abstract}
Despite the implementation of internet patient portals into the safety net after the introduction of the Affordable Care Act in the United States, little attention has been paid to the process of engaging vulnerable patients into these portals. The portal is a health technology tool that was developed with a mainstream, English-speaking audience in mind. Thus, there are valid concerns that such technologies will actually exacerbate health care disparities, conferring further advantages to the already advantaged. In this paper, we describe a framework for portal engagement (awareness, registration, and use) among safety net patients. We incorporate the experiences in the Los Angeles County Department of Health Services to illustrate important contextual factors for portal outreach in our safety net. Finally, we discuss considerations for moving forward with health technology in the safety net as the next version of patient portals are being developed.
\end{abstract}

(J Med Internet Res 2020;22(10):e16835) doi: 10.2196/16835

\section{KEYWORDS}

patient portal; safety net; health disparities; digital divide

\section{Introduction: A Patient Portal Arrives to the Safety Net}

Online patient health portals, also known as "patient portals" or "portals," are two-way communication systems that are tethered to a patient's electronic health record (EHR) [1]. Portals allow patients to manage many aspects of their health care from the convenience of their internet-connected device. Some studies have found that use of patient portals may improve quality of care and health outcomes, particularly for patients with chronic conditions such as diabetes mellitus [1-10].

Largely driven by the financial incentives of the Health Information Technology for Economic and Clinical Health Meaningful Use program (as part of the 2014 US federal health care reform), patient portals have rapidly expanded [2,11-13]. In the last few years, many safety net systems - which are health systems that provide a significant level of care to minority, low-income, limited English proficient (LEP), and other vulnerable patients-have begun implementing patient portals. This innovation has given safety net health systems a new mechanism to directly share information and communicate with patients online. Since many vulnerable patients face barriers to in-person visits (such as taking unpaid time off from needed work), this telemedicine mechanism has potential for enhancing their care. Most notably, the coronavirus-19 (COVID-19) disease pandemic forced health systems to scale back on physical patient visits, and in-person patient education and engagement dramatically. With no established telemedicine workflows in place, this situation can exacerbate the health disparities for 
these patients who are already at higher risk of poor disease management outcomes. Recent events have therefore highlighted the need to prioritize the integral role of the patient portal for care delivery in the Los Angeles safety net, and safety nets across the country.

Much of the prior literature related to patient portals and low-income populations has focused on the barriers posed by the digital divide; that is, the fact that many vulnerable populations lack the digital access, capacity, and interest to use a portal [14-28]. However, prior national studies suggest that the racial/ethnic and socioeconomic digital divide is shrinking, and that there are no racial/ethnic differences among people accessing the internet via mobile phones (about $60 \%$ of US adults) $[28,29]$. Furthermore, new data corroborate and expand upon prior work showing a high level of interest in portals among low-income, LEP, Medicaid, and public hospital patients [30-34]. Thus, the aforementioned barriers to the use of portals by safety net populations may be diminishing, and this population may be increasingly ready and eager to use the patient portal.

Despite these findings, little attention has been paid to the process of engaging vulnerable patients into an online health portal. This is especially problematic as the portal is a health technology tool that was developed with a mainstream, English-speaking audience in mind [13,35,36]. There are valid concerns that such technologies, including the patient portal, will actually exacerbate health care disparities, conferring "further advantages to the already advantaged," a tenet of the Inverse Care Law [26].

As safety net health systems continue to implement patient portals [37], important questions remain about the factors that influence safety net portal registration and use, and the portal education strategies that will be effective among these vulnerable patients $[13,15,35,38-40]$. Health systems that are developing portals for vulnerable populations might benefit from an underlying framework that takes into consideration the unique needs of these populations.

In this paper, we describe our portal engagement process (awareness, registration, and use) for safety net patients. We then incorporate the experiences in the Los Angeles County Department of Health Services (LAC DHS) between 2015 and 2019 to illustrate important contextual factors in our safety net's portal development. Finally, we discuss considerations for moving forward with health technology in the safety net as the next version of patient portals are being developed.

\section{Development of a Framework for Portal Engagement Among Vulnerable Patients in the $L A C D H S$}

\section{Overview of Formative Findings}

The LAC DHS, as the second largest municipal health safety net system in the United States, launched its English-Spanish patient portal in March 2015, with one of the few bilingual interfaces in the nation. The LAC DHS serves 600,000 unique patients each year, with 400,000 patients empaneled to its primary care clinics. Over half of the LAC DHS population is LEP, with the majority of these patients being Spanish speakers. At its inception, patients were able to view lab results, medication lists, and vital signs; additional features were added progressively. Figure 1 outlines the timing of various portal features in the LAC DHS MyWellness patient portal and accompanying portal registration data.

Many of these portal developments/improvements stemmed from patient input that we received on the frontlines. From January to March 2016, the LAC DHS performed a system-wide quality improvement internal survey of patients waiting in line for medical records. Patients were asked to fill out a paper or tablet survey to self-describe any internet access (including public and private access), knowledge about the MyWellness patient portal, and interest in health information on the MyWellness patient portal. We systematically randomly surveyed almost 200 patients, $73.0 \%(n=146)$ of whom reported having access to the internet. Only $20.0 \%(n=40)$ of patients were aware of the patient portal, and $45.0 \%(n=90)$ of those surveyed indicated interest in learning more about the portal.

We conducted focus groups in the summer of 2017 among LAC DHS patients with chronic conditions to better understand perceptions of the portal and to obtain patient-centered recommendations for implementation [41]. Important themes from these focus groups were that we needed to provide dedicated patient guidance for both portal enrollment and portal navigation. One of the LAC DHS sites received a Catalyst human-centered design grant through the Center for Care Innovations to better understand the patient process and experience around trying to register for the patient portal. This formative work culminated in the development of a novel framework to outline factors affecting portal registration and use in the safety net, which is partly based on the technology acceptance model [42]. As shown in Figure 2, the framework outlines factors under the domains of patient characteristics, patient experience with technology, patient beliefs and perceptions, and engagement initiatives by safety net health systems that will impact (1) patient awareness of a patient portal, leading to (2) patient registration, and ultimately result in (3) sustained use of the portal by patients. 
Figure 1. Los Angeles County Department of Health Services portal features timeline and percentage of empaneled primary care patients enrolled at each stage.

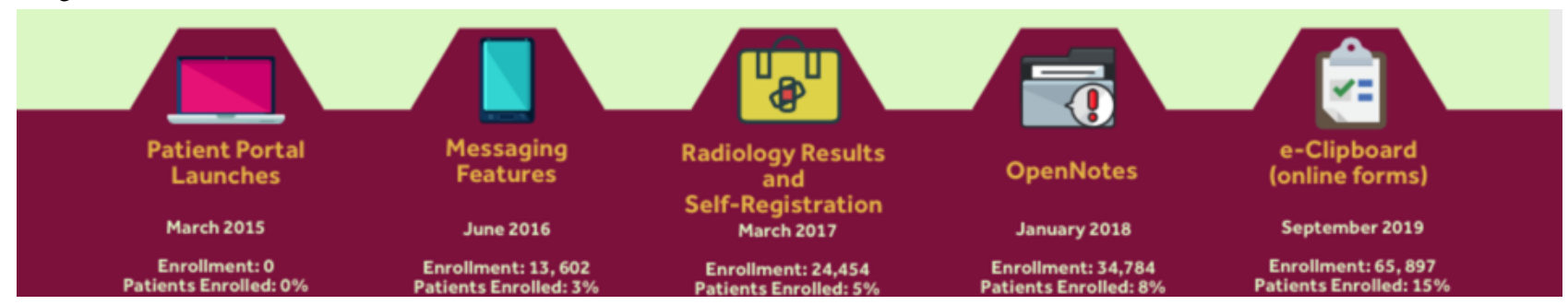

Figure 2. Implementation framework for portal registration and use among safety net patients.

\section{Factors that influence Portal Use in the Los Angeles Safety Net}

\section{PATIENT CHARACTERISTICS}

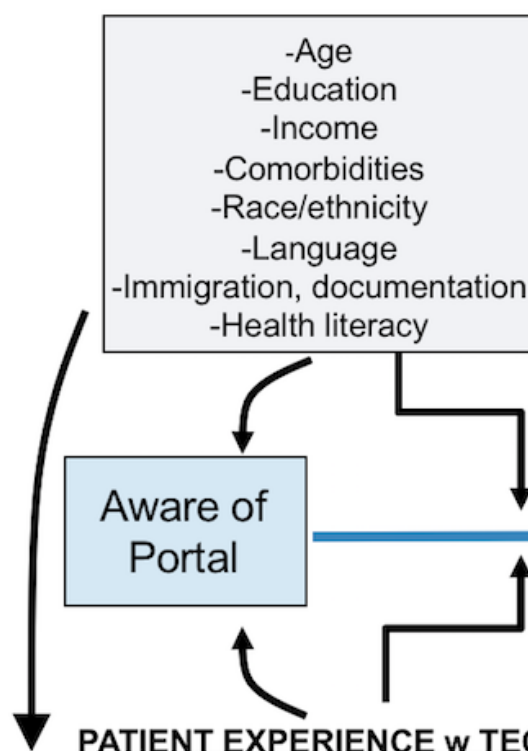

SAFETY NET PORTAL ENGAGEMENT

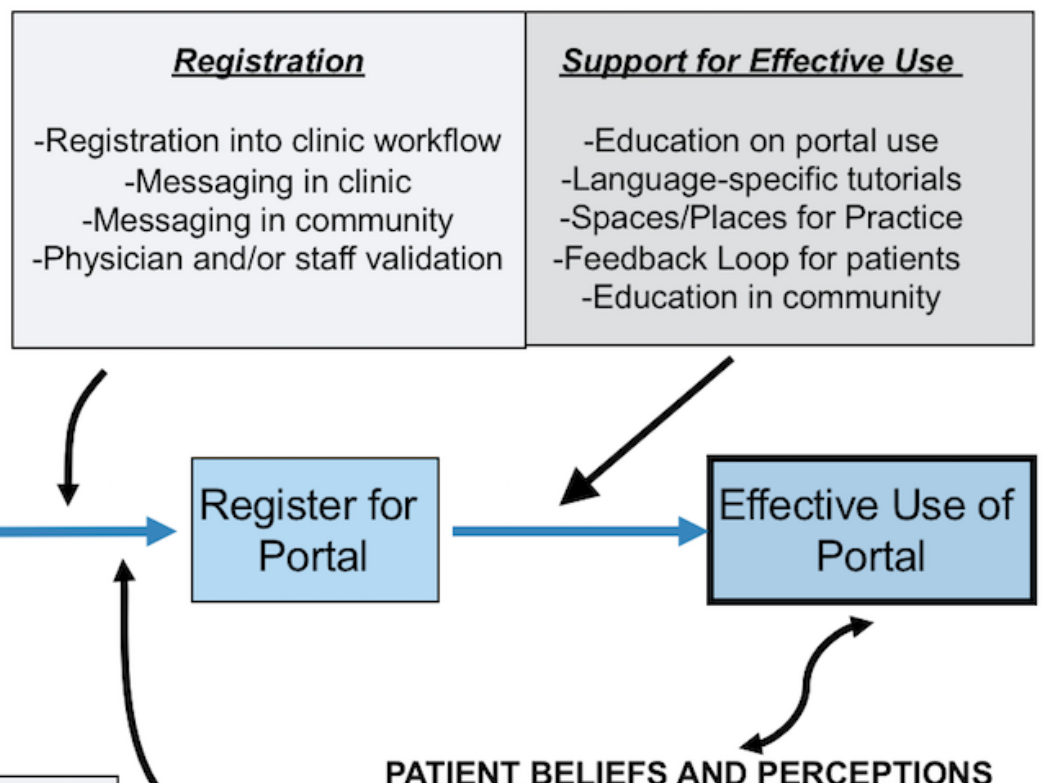

PATIENT BELIEFS AND PERCEPTIONS

-Digital access

-Technology understanding

-Portal awareness/familiarity

-Has used internet for health information -Access to friends/family who can help w tech

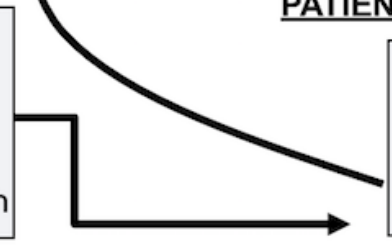

-Perceived portal utility -Lack of confidence to use tech

-Mistrust in health system

-Fatalism/ambivalence
Our formative findings and framework coincide with some of the conclusions provided by Grossman et al [43] in 2019. After reviewing over 100 studies about patient portal use among vulnerable populations, they found that individually focused interventions had the most evidence for increasing use in vulnerable populations. They recommended that research should "move beyond identifying disparities to systematically addressing them at multiple levels" for these patients [43]. In that vein, our work over the last 5 years has led to three actionable steps in facilitating portal uptake among our patients, which we now recommend as a model to other safety nets and EHR companies serving these patient populations:

\section{Step 1: Remove Unnecessary Patient Process Barriers in Enrolling for the Portal}

Recent studies have provided recommendations on patient- and system-level interventions to increase registration and use of the portal (ie, opt-out enrollment strategies, patient portal training) [43]. However, many of these recommendations will depend on the specific restrictions and parameters of the EHR vendor. For our patient population, the LAC DHS originally required an email address and a social security number (SSN) as a unique patient identifier (to receive a patient portal activation code). Privacy is paramount as it pertains to health data and security; however, authentication that requires an email address for portal enrollment can widen digital disparities to data access in the safety net. An acceptable alternative could be sending the activation code via a cell phone number (although this does not overcome the barrier that patients of low socioeconomic status may share phones). At one of our largest LAC DHS sites, patients between the ages of 18-64 have $75 \%-87 \%$ cell phone ownership and $49 \%$ of the patients aged $>65$ years report cell phone ownership. Authentication processes that require an $\mathrm{SSN}$ in safety net populations are 
especially problematic, given that many immigrant patients may lack this information or even fear a process asking for it, owing to their (or their family members') documentation status. In response to these issues, we worked with our vendor to eliminate these steps and replace them with acceptable enrollment alternatives (eg, self-registration, medical record number identifiers).

To improve equity to data access, we suggest that EHR vendors improve the ease of enrollment and give patients options for multifactor authentication that do not require an email address or secure/stigmatized information.

\section{Step 2: Rethink Portal Engagement With a Patient-Centered Approach}

The creation of LAC DHS Patient Portal Summits have brought together leadership, patient advocate groups, front desk staff, and clinicians to uniformly design engagement materials and staff incentive programs that best advance portal registration among our patients (even in low-resource settings). With support from a 2018 Center for Care Innovation's Catalyst grant, we created portal engagement materials that could eventually be administered by any LAC DHS staff member. Patients, nursing, staff, and physicians from all LAC DHS sites provided input over the course of 18 months. To date, this collaboration has resulted in a training curriculum for LAC DHS staff on portal engagement and engagement videos featuring the portal, developed by (and showing) patient and staff members and displayed in waiting rooms across our system in multiple languages [42,44]. From November 2018 to January 2019, a patient portal enrollment competition took place to further engage frontline staff in enrolling and engaging patients in the portal.

Based on concepts that were prominent in our own formative work with patients, we suggest that safety net systems improve their portal messaging approaches to focus on: (a) validation of the portal by health care workers, (b) messaging about the portal that is useful to a patient's daily life and relevant to their personal health [45], and (c) educational scripts that incorporate family/community members.

\section{Step 3: Partner With the EHR Vendor to Focus on an Appropriate User Interface}

Our data show that the majority of LAC DHS patients who access the portal do so via their mobile devices (70\%), whereas portals from nonsafety-net patients tend to more frequently be accessed via a desktop [28]. Pew Research surveys on smartphone use describe a phenomenon of "smartphone dependence" among low-income and minority populations [28]. Cable internet is increasingly expensive, and low-income communities increasingly depend on smartphone internet access for their overall online access. This is particularly important to keep in mind as patients are accessing health data. At the LAC DHS, we recognize that our internet strategies must be "mobile first." Accordingly, true mobile-friendly experiences became a ripe area for co-design with our patients, health system, and EHR vendors. In addition to prioritizing the improvement of our mobile app version of the MyWellness portal over the desktop app, and ensuring that all portal features are available on the mobile version, we are also working with our EHR vendor on the following aspects: improving usability of the portal website for non-English speakers, making messaging more obvious on the website, improving patient education options to "learn more" about a lab or health condition, using multiple languages, creating a patient virtual feedback group, and forming a staff "super-user and champions" group to report back to our EHR vendor regarding usability concerns for our patients.

Another limitation has been the unwillingness of large portal vendors to allow the use of images from the portal in creation of training materials. This is a simple barrier that must be addressed, and just another example of how health systems should better partner with their EHR vendors on relevant patient portal operations and research [46]. We recognize that improving the user interface and usability will be a key challenge for this partnership, although there are published models that can help us better understand how users interact with this technology and the resources that may be necessary to support its use [47]. Portals are not alone in this limitation, as most digital health apps and platforms do not meet basic health literacy or language standards. Indeed, there are no clear standards for digital engagement in health care, and this gap must be addressed if the portal is to become completely accessible for diverse populations.

Despite very specific standards for health literacy of written materials, this has not been translated to digital tools. Therefore, we recommend more transparency and inclusion around testing strategies to ensure that safety net populations are active participants in these testing phases.

\section{Patient Portal 2.0: Reimagining the Next Generation of Portals for Improved Accessibility to Safety Net Patients}

\section{Key Questions}

If health technology is destined to serve even the most vulnerable patients, medical informatics research must answer the following questions: How can portals be made more accessible from the patient's perspective? What do safety net patients need from patient portals? By focusing on patients from vulnerable backgrounds, the safety net setting becomes a real-life laboratory for developing portals that will improve portal accessibility for all populations. We highlight the following patient-centered points (findings from our formative work) in reimagining the next version of portals.

\section{Connect to the Safety Net Patient's "Home" Team}

Outside of the health care setting, there is already a "team" surrounding many of our patients, made up of family members and friends who serve as caregivers and trusted confidants for health decisions. Therefore we need to make it easier to connect digitally with these trusted team members (in addition to the individual patient) if the patient portal is to be used as a primary health management tool moving forward.

To first address this, there must be better options around "level of access" to patient data through proxy relationships, especially 
when patient privacy and security remain a top level of concern among safety net patients. Our LAC DHS physicians have reported the need to provide limited portal views of "sensitive" information (eg, HIV results, intravenous drug use history) for patients who rely on family or friends as informal or formal caregivers. The option to share the portal with the patient's team may be foregone in some cases because of the current "all-or-nothing" access approach to health information via a proxy login. One solution to this dilemma is to allow patients the ability to choose what level of proxy access a caregiver/family member will have. In reality, this is a feature that should be available to all patients, and will particularly resonate with adolescent and geriatric populations, and for patients with disabilities in other health care settings.

\section{Create a Virtual Home for Patient-Centered Care}

What if the portal 2.0 were more than a data repository and messaging/scheduling hub? Patients are starting to fill out forms online through the patient portal, and such patient-generated data should be helpful to health care systems for tailored patient care and improvements to the system. What if the portal could also suggest content and experiences for patients? For example, a patient recently diagnosed with heart failure could receive suggestions from the portal for post-discharge follow-up videos, and health systems could track these engagement metrics. The portal could also push information to the patient about heart failure options for disease monitoring, such as online weight $\operatorname{logs}$ or a wireless scale. Patients with prediabetes who want support for lifestyle modification could be directed to locations for free or low-cost exercise programs in recreation centers or parks. Patients and providers have already suggested a desire for a portal that can collect patient-reported outcome metrics and deliver personalized feedback [48].

Currently, health systems are reactive; that is, we often wait for patients to approach our team with questions before we address health issues and socioemotional concerns. However, if a patient fills out a "Know Me" questionnaire and sets personal weight loss goals, the portal might be able to suggest culturally tailored nutrition and physical activity community resources for the patient based on their profile, even before visiting the clinic. As another example, if housing instability is listed as a problem in the EHR, the portal should potentially be able to push local resource notifications for housing or legal aid services. When "food insecurity" is recognized and coded in the EHR, could the portal then push notifications about food resources that are tailored to the patient's home address or the geolocation on their phone? The safety net can help us re-envision the portal as a place where: (1) patients can be connected with social resources based on their needs, rooted in the social determinants of health; (2) patients can "check in" on health indicators, track the progression of personal indicators and goals; and (3) access culturally tailored and language-appropriate videos, podcasts, and written materials based on the patients' underlying health conditions.

\section{Moving Beyond Meaningful Use}

To achieve this vision of the patient portal, we must grade new portals based on metrics that move beyond meaningful use, which have previously only focused on patients' log-in, download, and exchange of data/messages with their health care team. EHR vendors are starting to understand the need to assist patients with self-management by exploring workflows to help patients fill out forms online to monitor chronic conditions, creating online interfaces for patients to log blood sugar and blood pressure levels, working to integrate devices such as smartwatches and connected devices (ie, wireless glucometers, blood pressure cuffs, weight scales), incorporating care manager and patient goals into their platforms, and integrating online platforms for community-based resources such as food banks, transportation assistance, and housing into the health record.

\section{Summary: How Patient Portals Will Meet the Needs of Safety Net Patients}

Safety net health systems provide health care for our most medically and socially fragile patients: populations that include patients with multiple morbid conditions, LEP, cognitive impairment, high-risk perinatal needs, physical and mental disabilities, low literacy, homelessness, substance use, justice system-affected, and a broad range of immigrant and refugee communities. Safety nets are the ideal places to develop and refine the next iterations of the EHR and the patient portal. Because the portal is a "gateway" to the use of other digital health interventions, it is also an avenue for intervention research and a modality for better understanding of what vulnerable patients need to more effectively interface with health technology.

A limitation of this paper is that we did not delve into the continual barriers that sustain the digital divide (having access to reliable internet, limited devices and data/storage, and patients' digital literacy). Although the digital divide seems to be shrinking, these recommendations should also be tempered with the knowledge that extreme disparities in internet access continue to exist for low-income populations, especially in certain areas of the country [49]. All of these systemic and patient-centered barriers should be addressed in a version of patient portal development that is more inclusive. To make this tool work for our most vulnerable populations, moving forward, we need to take intentional steps to ensure that the patient portal can be effectively and efficiently deployed in health systems that serve these high-risk patients. To achieve these goals, we must (1) remove unnecessary patient process barriers in enrolling for the portal; (2) redesign engagement materials with a patient-centered approach; (3) partner with EHR vendors to focus on the user interface and usability from a safety net patient perspective; (4) engage trusted family members and caregivers to create a flexible, patient-friendly mechanism for proxy access; (5) create a virtual home for patient-centered care that includes addressing social determinants, preventive care, and chronic care; and (6) redefine the metrics of portal success, as seen in the safety net.

Finally, we would be remiss in not emphasizing that health systems around the country are quickly developing remote strategies to reach out to patients for health management resources and education as in-person services shrink, secondary to the COVID-19 pandemic, and that the patient portal is an integral part of this outreach plan. Thus, redesigning the patient 
portal so that it effectively reaches and impacts our most vulnerable patients is an important step to improve health care access for the entire US population. These uncertain and challenging times in our history are an opportunity to significantly move the needle in digital health, and create a patient portal that works for even the most vulnerable patients in this new era of healthcare- making sure that no patient is left behind.

\section{Acknowledgments}

AC is supported by the AHRQ/PCORI KL12HS0260407-01(MOI) award via the Stakeholder-Partnered Implementation Research and Innovation Translation (Spirit) Program. The authors acknowledge scholarly feedback from faculty members of the UCLA Clinical and Translational Science Institute (CTSI) Patient Portal Research Workgroup, which is supported by the National Center for Advancing Translational Sciences (NCATS), National Institutes of Health, through grant number UL1TR001881.

\section{Conflicts of Interest}

None declared.

\section{References}

1. Kruse CS, Bolton K, Freriks G. The effect of patient portals on quality outcomes and its implications to meaningful use: a systematic review. J Med Internet Res 2015 Feb 10;17(2):e44 [FREE Full text] [doi: 10.2196/jmir.3171] [Medline: 25669240]

2. Kamo N, Bender AJ, Kalmady K, Blackmore CC. Meaningful use of the electronic patient portal - Virginia Mason's journey to create the perfect online patient experience. Healthc (Amst) 2017 Dec;5(4):221-226. [doi: 10.1016/j.hjdsi.2016.09.003] [Medline: 27727028]

3. Goldzweig C, Towfigh A, Paige N, Orshansky G, Haggstrom D, Beroes J, Evidence-based Synthesis Program. Systematic Review: Secure Messaging Between Providers and Patients, and Patients' Access to Their Own Medical Record. Evidence on Health Outcomes, Satisfaction, Efficiency and Attitudes. Washington DC: Department of Veterans Affairs (US); 2012.

4. Ralston JD, Hirsch IB, Hoath J, Mullen M, Cheadle A, Goldberg HI. Web-based collaborative care for type 2 diabetes: a pilot randomized trial. Diabetes Care 2009 Feb;32(2):234-239 [FREE Full text] [doi: 10.2337/dc08-1220] [Medline: $\underline{19017773]}$

5. Sarkar U, Lyles CR, Parker MM, Allen J, Nguyen R, Moffet HH, et al. Use of the refill function through an online patient portal is associated with improved adherence to statins in an integrated health system. Med Care 2014 Mar;52(3):194-201 [FREE Full text] [doi: 10.1097/MLR.0000000000000069] [Medline: 24374412]

6. Harris LT, Haneuse SJ, Martin DP, Ralston JD. Diabetes quality of care and outpatient utilization associated with electronic patient-provider messaging: a cross-sectional analysis. Diabetes Care 2009 Jul;32(7):1182-1187 [FREE Full text] [doi: 10.2337/dc08-1771] [Medline: 19366959 ]

7. Tenforde M, Nowacki A, Jain A, Hickner J. The association between personal health record use and diabetes quality measures. J Gen Intern Med 2012 Apr;27(4):420-424 [FREE Full text] [doi: 10.1007/s11606-011-1889-0] [Medline: 22005937]

8. Reed M, Huang J, Graetz I, Brand R, Hsu J, Fireman B, et al. Outpatient electronic health records and the clinical care and outcomes of patients with diabetes mellitus. Ann Intern Med 2012 Oct 02;157(7):482-489 [FREE Full text] [doi: 10.7326/0003-4819-157-7-201210020-00004] [Medline: 23027319]

9. Halamka JD, Mandl KD, Tang PC. Early experiences with personal health records. J Am Med Inform Assoc 2008;15(1):1-7 [FREE Full text] [doi: 10.1197/jamia.M2562] [Medline: 17947615]

10. Zhou YY, Kanter MH, Wang JJ, Garrido T. Improved quality at Kaiser Permanente through e-mail between physicians and patients. Health Aff (Millwood) $2010 \mathrm{Jul}$;29(7):1370-1375. [doi: 10.1377/hlthaff.2010.0048] [Medline: 20606190]

11. Blumenthal D, Tavenner M. The "meaningful use" regulation for electronic health records. N Engl J Med 2010 Aug 05;363(6):501-504. [doi: 10.1056/NEJMp1006114] [Medline: 20647183]

12. 2014 National Healthcare Quality \& Disparities Report. Agency for Healthcare Research and Quality. Rockville, MD; 2014 Oct. URL: https://archive.ahrq.gov/research/findings/nhqrdr/nhqdr14/index.html [accessed 2019-10-20]

13. Lyles CR, Fruchterman J, Youdelman M, Schillinger D. Legal, Practical, and Ethical Considerations for Making Online Patient Portals Accessible for All. Am J Public Health 2017 Oct;107(10):1608-1611. [doi: 10.2105/AJPH.2017.303933] [Medline: 28817324]

14. Sequist TD. Health information technology and disparities in quality of care. J Gen Intern Med 2011 Oct;26(10):1084-1085 [FREE Full text] [doi: 10.1007/s11606-011-1812-8] [Medline: 21809173]

15. Smith SG, O'Conor R, Aitken W, Curtis LM, Wolf MS, Goel MS. Disparities in registration and use of an online patient portal among older adults: findings from the LitCog cohort. J Am Med Inform Assoc 2015 Jul;22(4):888-895 [FREE Full text] [doi: 10.1093/jamia/ocv025] [Medline: 25914099]

16. Arora S, Ford K, Terp S, Abramson T, Ruiz R, Camilon M, et al. Describing the evolution of mobile technology usage for Latino patients and comparing findings to national mHealth estimates. J Am Med Inform Assoc 2016 Sep;23(5):979-983 [FREE Full text] [doi: 10.1093/jamia/ocv203] [Medline: 26995564] 
17. File T. Digital Divides: A connectivity continuum for the United States. Data from the Current Population Survey. 2012 Sep 19. URL: http://paa2013.princeton.edu/papers/130743 [accessed 2019-10-20] [WebCite Cache ID https://paa2013.princeton.edu/papers/130743]

18. File T. Digital Divides: A Connectivity Continuum for the United States. : Social and Economic Statistics Division, U.S. Census Bureau, U.S. Department of Commerce; 2013 Apr 11 Presented at: Annual Meeting of the Population Association of America; April 2013; New Orleans, LA p. 11-13.

19. File T. Computer and Internet Use in the United States. In: Current Population Survey Reports, P20-568. Washington, DC: US Census Bureau; 2013:1-14.

20. File T, Ryan C. Computer and Internet Use in the United States: 2013. American Community Survey Reports, ACS-28. U.S. Census Bureau, Washington DC. 2013 May 05. URL: https://www.census.gov/history/pdf/acs-internet2013.pdf [accessed 2020-09-05]

21. Kontos E, Blake KD, Chou WS, Prestin A. Predictors of eHealth usage: insights on the digital divide from the Health Information National Trends Survey 2012. J Med Internet Res 2014 Jul 16;16(7):e172 [FREE Full text] [doi: 10.2196/jmir.3117] [Medline: 25048379]

22. Laz TH, Berenson AB. Racial and ethnic disparities in internet use for seeking health information among young women. J Health Commun 2013;18(2):250-260 [FREE Full text] [doi: 10.1080/10810730.2012.707292] [Medline: 23130608]

23. Livingston G. Latinos and digital technology, 2010. Pew Research Center, Hispanic Trends. URL: http://www. pewhispanic.org/2011/02/09/latinos-and-digital-technology-2010/ [accessed 2018-02-20]

24. Perzynski AT, Roach MJ, Shick S, Callahan B, Gunzler D, Cebul R, et al. Patient portals and broadband internet inequality. J Am Med Inform Assoc 2017 Sep 01;24(5):927-932 [FREE Full text] [doi: 10.1093/jamia/ocx020] [Medline: 28371853]

25. Ratanawongsa N, Barton JL, Lyles CR, Wu M, Yelin EH, Martinez D, et al. Computer use, language, and literacy in safety net clinic communication. J Am Med Inform Assoc 2017 Jan;24(1):106-112 [FREE Full text] [doi: 10.1093/jamia/ocw062] [Medline: 27274017]

26. Schillinger D. Literacy and health communication: reversing the 'inverse care law'. Am J Bioeth 2007 Nov;7(11):15-8; discussion W1. [doi: 10.1080/15265160701638553] [Medline: 18027291]

27. Turner-Lee N, Brian S, Joseph M. Minorities Mobile Broadband and the Management of Chronic Diseases. Washington, DC: Joint Center for Political and Economic Studies; 2012.

28. Zickuhr K, Smith A. Digital Differences. Pew Research Center, Internet \& Technology. Washington, DC: Pew Internet and American Life Project; 2012 Apr 13. URL: http://www.pewinternet.org/2012/04/13/digital-differences/ [accessed 2018-02-20]

29. Gonzalez M, Sanders-Jackson A, Emory J. Online Health Information-Seeking Behavior and Confidence in Filling Out Online Forms Among Latinos: A Cross-Sectional Analysis of the California Health Interview Survey, 2011-2012. J Med Internet Res 2016 Jul 04;18(7):e184 [FREE Full text] [doi: 10.2196/jmir.5065] [Medline: 27377466]

30. Dhanireddy S, Walker J, Reisch L, Oster N, Delbanco T, Elmore JG. The urban underserved: attitudes towards gaining full access to electronic medical records. Health Expect 2014 Oct;17(5):724-732 [FREE Full text] [doi: 10.1111/j.1369-7625.2012.00799.x] [Medline: 22738155]

31. Lobach DF, Willis JM, Macri JM, Simo J, Anstrom KJ. Perceptions of Medicaid beneficiaries regarding the usefulness of accessing personal health information and services through a patient Internet portal. AMIA Annu Symp Proc 2006:509-513 [FREE Full text] [Medline: 17238393]

32. Mirsky JB, Tieu L, Lyles C, Sarkar U. A Mixed-Methods Study of Patient-Provider E-Mail Content in a Safety-Net Setting. J Health Commun 2016;21(1):85-91 [FREE Full text] [doi: 10.1080/10810730.2015.1033118] [Medline: 26332306]

33. Ochoa A, Kitayama K, Uijtdehaage S, Vermillion M, Eaton M, Carpio F, et al. Patient and provider perspectives on the potential value and use of a bilingual online patient portal in a Spanish-speaking safety-net population. J Am Med Inform Assoc 2017 Nov 01;24(6):1160-1164. [doi: 10.1093/jamia/ocx040] [Medline: 28460130]

34. Schickedanz A, Huang D, Lopez A, Cheung E, Lyles CR, Bodenheimer T, et al. Access, interest, and attitudes toward electronic communication for health care among patients in the medical safety net. J Gen Intern Med 2013 Jul;28(7):914-920 [FREE Full text] [doi: 10.1007/s11606-012-2329-5] [Medline: 23423453]

35. Irizarry T, DeVito Dabbs A, Curran CR. Patient Portals and Patient Engagement: A State of the Science Review. J Med Internet Res 2015 Jun 23;17(6):e148 [FREE Full text] [doi: 10.2196/jmir.4255] [Medline: 26104044]

36. Lyles C, Schillinger D, Sarkar U. Connecting the Dots: Health Information Technology Expansion and Health Disparities. PLoS Med 2015 Jul;12(7):e1001852 [FREE Full text] [doi: 10.1371/journal.pmed.1001852] [Medline: 26172977]

37. Casillas A, Moreno G, Grotts J, Tseng C, Morales LS. A Digital Language Divide? The Relationship between Internet Medication Refills and Medication Adherence among Limited English Proficient (LEP) Patients. J Racial Ethn Health Disparities 2018 Dec;5(6):1373-1380 [ [FREE Full text] [doi: 10.1007/s40615-018-0487-9] [Medline: 29600351]

38. Tieu L, Sarkar U, Schillinger D, Ralston JD, Ratanawongsa N, Pasick R, et al. Barriers and Facilitators to Online Portal Use Among Patients and Caregivers in a Safety Net Health Care System: A Qualitative Study. J Med Internet Res 2015 Dec 03;17(12):e275 [FREE Full text] [doi: 10.2196/jmir.4847] [Medline: 26681155] 
39. Tieu L, Schillinger D, Sarkar U, Hoskote M, Hahn KJ, Ratanawongsa N, et al. Online patient websites for electronic health record access among vulnerable populations: portals to nowhere? J Am Med Inform Assoc 2017 Apr 01;24(e1):e47-e54 [FREE Full text] [doi: 10.1093/jamia/ocw098] [Medline: 27402138]

40. Sheon AR, Bolen SD, Callahan B, Shick S, Perzynski AT. Addressing Disparities in Diabetes Management Through Novel Approaches to Encourage Technology Adoption and Use. JMIR Diabetes 2017 Jul 13;2(2):e16 [FREE Full text] [doi: 10.2196/diabetes.6751] [Medline: 30291090]

41. Casillas A, Perez-Aguilar G, Abhat A, Gutierrez G, Olmos-Ochoa TT, Mendez C, et al. Su salud a la mano (your health at hand): patient perceptions about a bilingual patient portal in the Los Angeles safety net. J Am Med Inform Assoc 2019 Dec 01;26(12):1525-1535 [FREE Full text] [doi: 10.1093/jamia/ocz115] [Medline: 31373362]

42. Scherer R, Siddiq F, Tondeur J. The technology acceptance model (TAM): A meta-analytic structural equation modeling approach to explaining teachers' adoption of digital technology in education. Comput Educ 2019 Jan;128:13-35. [doi: 10.1016/j.compedu.2018.09.009]

43. Grossman LV, Masterson Creber RM, Benda NC, Wright D, Vawdrey DK, Ancker JS. Interventions to increase patient portal use in vulnerable populations: a systematic review. J Am Med Inform Assoc 2019 Aug 01;26(8-9):855-870 [FREE Full text] [doi: $10.1093 /$ jamia/ocz023] [Medline: $\underline{\text { 30958532] }}$

44. Quach T. Mrs Garcia Intro. YouTube. URL: https://www.youtube.com/watch?v=kIWZFRMtPD8\&feature=youtu.be [accessed 2019-10-20]

45. Nambisan P. Factors that impact Patient Web Portal Readiness (PWPR) among the underserved. Int J Med Inform 2017 Jun;102:62-70. [doi: 10.1016/j.ijmedinf.2017.03.004] [Medline: 28495349]

46. Strudwick G, Kuziemsky C, Booth R, Rossetti S, Chyjek A, Sakal M, et al. Three Methods for Engaging Patients and Care Partners in Patient Portal Research. Stud Health Technol Inform 2019 Aug 21;264:1984-1985. [doi: 10.3233/SHTI190746] [Medline: 31438440$]$

47. Yen P, Walker DM, Smith JMG, Zhou MP, Menser TL, McAlearney AS. Usability evaluation of a commercial inpatient portal. Int J Med Inform 2018 Feb;110:10-18. [doi: 10.1016/j.ijmedinf.2017.11.007] [Medline: 29331248]

48. Cronin RM, Conway D, Condon D, Jerome RN, Byrne DW, Harris PA. Patient and healthcare provider views on a patient-reported outcomes portal. J Am Med Inform Assoc 2018 Nov 01;25(11):1470-1480 [FREE Full text] [doi: 10.1093/jamia/ocy111] [Medline: $\underline{30239733]}$

49. Callahan B. Worst Connected Cities of 2018. National Digital Inclusion Alliance. URL: https://www.digitalinclusion.org/ blog/2019/10/23/worst-connected-cities-of-2018/ [accessed 2020-06-07]

\author{
Abbreviations \\ COVID-19: coronavirus disease 2019 \\ EHR: electronic health record \\ LAC DHS: Los Angeles County Department of Health Services \\ LEP: limited English proficient \\ SSN: social security number
}

Edited by G Eysenbach; submitted 29.10.19; peer-reviewed by A Sheon, G Germinario; comments to author 28.02.20; revised version
received 25.06.20; accepted 07.07.20; published 23.10.20
Please cite as:
Casillas A, Abhat A, Mahajan A, Moreno G, Brown AF, Simmons S, Szilagyi P
Portals of Change: How Patient Portals Will Ultimately Work for Safety Net Populations
J Med Internet Res 2020;22(10):e16835
URL: $\underline{\text { https://www.jmir.org/2020/10/e16835 }}$
doi: $10.2196 / 16835$
PMID: $\underline{3094732}$

(C)Alejandra Casillas, Anshu Abhat, Anish Mahajan, Gerardo Moreno, Arleen F Brown, Sara Simmons, Peter Szilagyi. Originally published in the Journal of Medical Internet Research (http://www.jmir.org), 23.10.2020. This is an open-access article distributed under the terms of the Creative Commons Attribution License (https://creativecommons.org/licenses/by/4.0/), which permits unrestricted use, distribution, and reproduction in any medium, provided the original work, first published in the Journal of Medical Internet Research, is properly cited. The complete bibliographic information, a link to the original publication on http://www.jmir.org/, as well as this copyright and license information must be included. 